\title{
Tacit Knowledge Sharing in Public Sector Departments in Kenya
}

\author{
Susan Njeri Wamitu \\ Department of Business, School of Business and Economics, Kenya Methodist University, Nyeri Campus, \\ Nyeri, Kenya \\ Email: suewamitu@yahoo.com
}

Received 29 December 2014; accepted 19 January 2015; published 22 January 2015

Copyright (C) 2015 by author and Scientific Research Publishing Inc.

This work is licensed under the Creative Commons Attribution International License (CC BY).

http://creativecommons.org/licenses/by/4.0/

(c) (i) Open Access

\begin{abstract}
Organizational employees know valuable information but sharing that information throughout the organization is a challenge. Organizational employees need to share problems, experiences, insights, templates, tools and best practices. Many organizations concentrate on hard technology as the only way to gain competitive advantage and ignore the very crucial strategy that gives it a competitive edge. Tacit knowledge well guarded in the employee's mind is the only non-imitable organizational resource (Senge, P., 1990) [1]. Knowledge focus is the third wave of human socioeconomic development, the first having been the agricultural age with wealth being defined as ownership of land and the second being the industrial age where wealth is based on ownership of capital e.g. factories. In the knowledge age, wealth is based upon the ownership of knowledge and the ability to use, create and use it to improve goods and services.This review wishes to expose the challenges of functional boundaries, communication, motivation and organizational culture on tacit knowledge sharing in Kenya public sector organizations. The review will be guided by the following theories: constructivism theory that advocates for creation of knowledge through individual constructs, self efficacy theory where persons believe on their ability to organize and execute courses of action necessary to achieve a goal and Nonaka's model of knowledge creation which demonstrates knowledge dynamics using the SECI model. The review will also look at other researcher's literature and display the relationship between tacit knowledge sharing and the four variables.
\end{abstract}

\section{Keywords}

Tacit Knowledge, Knowledge Sharing, SECI, Functional Boundaries, Organizational Culture

\section{Introduction}

Knowledge management is as old as mankind though its eminent debut can be traced in the late forties during 
the Second World War when it was noted that upon successive building of fighter planes, fewer defects were reported and this was associated with knowledge sharing. The early industrial age saw the ancient man make improvements on the survival tools which improved in quality as he made one tool after the other, each time realizing fewer defects because of perfection derived from experience. Upon such understanding, man decided to start saving the experience gained in forms that can be retrieved if need arises. This brought about the concept of learning that encouraged quality production in masses that came to warrant exchange of products in form of barter trade.

Several notable gurus are associated with the field of knowledge management, chief among them being Drucker, P. (1999) [2], Senge, P. (1990) [1] and Strassmann, P. (1985) [3] who emphasized on the importance of knowledge as a crucial component in organizational learning. Other great contributors in this field are Everret, R. (1970) [4] in his book (Diffusion of Innovation) and Allen, T. (2006) [5] in his book on Research on Information and Technology Transfer. This period (1970's) saw many gurus concentrate on knowledge production, usage and how the same can be diffused across organizations. The 80's laid emphasis on knowledge as a tool of competitive advantage with such terms when knowledge acquisition taking prominence. The 90's gave rise to institution's initiative of managing knowledge and as such, knowledge management reviews and articles like Sloan Management Review, Organizational Science, and Harvard Business Review came up. The same period saw such books as the "Knowledge Value Revolution" by Sakaiya, T. (1999) [6] and the "Fifth Discipline" by Senge, P. et al. (1994) [7]. The press took up KM around the same period with a publication "Brainpower" by Tom Stewart in the Fortune Magazine. In 1994, IKMU which represents KM network, went online and this acted as a springboard that made KM go viral with increased KM seminars and conferences which have dominated the world even today. KM complements total quality management, business process reengineering and benchmarking which may not have achieved much as far as competitive advantage is concerned. Knowledge by its very nature is non imitable and as such it is a unique resource that should be nurtured whatever the cost.

\section{An Overview of KM Components}

$\mathrm{KM}$ is the name of a concept in which an enterprise consciously and comprehensively gathers, organizes shares and analyses its knowledge in terms of resources, documents and people skills (Augus, J. \& Jeeto, P., 1998) [8]. Ron Young, the CEO of Knowledge Associate International, defined KM as the discipline that enables individuals, teams and entire organization to collectively and systematically create, share and apply knowledge, to better achieve their objectives. Angus, J. \& Jeeto, P. (1998) [8] assembled a 4-process view of KM.

As is illustrated from Table 1, knowledge creation starts with gathering (process view $i$ ) which involves collecting relevant information for creating the desired knowledge. Process view ii involves organizing the data corrected and putting it into meaningful form. The third phase (process view iii) involves refining the organized data to enhance its form and understandability. The last phase (process view iv) disseminating information to those who desire it.

From Augus, J. and Jeeto, P.'s projection, sharing is a part of a wider component of KM process of disseminating. Tacit knowledge consists often of habits and culture that we do not recognize in us. It is noted in the way

Table 1. Four process view of knowledge creation.

\begin{tabular}{cc}
\hline Major Process & Activities \\
Gathering & Data Entry \\
\hline process view ) & Voice Input, Searching for Information, Scanning, \\
Crganizing & Cataloguing, Indexing, Filtering, Linking \\
\hline (process view ii) & Contextualizing \\
Refining & Collaboration \\
(process view iii) & Compacting \\
& Projecting \\
& Mining \\
\hline Disseminating & Flow \\
(process view iv) & Sharing \\
& Alert \\
\end{tabular}

Source: Augus, J. \& Jeeto, P. (1998) [8]. 
a person thinks. It is the unwritten rules or norms of the organization; those things that employees learn over time are difficult to incorporate into a training or orientation program. It is highly personalized knowledge which is hard to formalize, making it difficult to communicate or share with others. It includes subject insights, institutions and launches. It is deeply in individuals' actions and experiences as well as in the ideals, values and emotions the individuals embrace. For tacit knowledge to be transmitted, it must be converted into words, models or numbers that anyone can understand (Nonaka, I. \& Takeuchi, H., 1995) [9]. There are two types of tacit knowledge. The technical dimensions is the kind of informal and hard to pin down skills or crafts often captured in the term "knowhow" e.g. master craftsmen develop a wealth of expertise on their fingertips after years of experience. Highly subjective and personal insights, intuitions, hunches and inspirations, derived from bodily experience, fall into this dimension (Augus, J. \& Jeeto, P., 1998) [8]. The cognitive dimension consists of beliefs, perceptions, ideals, values, emotions and mental models which are so ingrained in us that we take them for granted. Though they cannot be articulated easily, they shape the way we perceive the world around us. There are four ways to capture tacit knowledge. The first one is mentoring a new employee which means assigning a mentor to new employees as a part of an orientation process and new hire acclimatization process where the mentor transfers and shares knowledge. The second focuses on employee retention. It is expensive to recruit, hire and train new employees, so the most effective way is to retain good employees. This helps to sustain a strong tacit knowledge base. The third is to provide employees with opportunities to share experiences. This can be as informal as weekly staff meetings or as formal as annual employee events. The forth is to document all processes. This process can be automated to have very detailed and written process sequenced step by step for every job. Worth noting is that tacit knowledge can offer comprehensive advantage because competitors have a difficult time replicating it.

A source of sustainable competitive advantage is organizational data or simple information because it gains competitive advantage when integrated with individual experience (Dougherty, V., 1999) [10]. Knowledge is first acquired at the individual level (Polanyi, M., 1962) [11] and effective transformation of it from the individual to the organizational level is essential for knowledge to become the basis of organizational capability (Kogut, B. \& Zander, U., 1995) [12].

Nonaka, I. (1994) [13] observes that knowledge creation is a spiraling process of interactions between explicit and tacit knowledge. There are four steps of knowledge conversion process. Socialization is the process that involves sharing of tacit knowledge between individuals by spending time, activities and actively working together on solving problems. Externalization involves the expression of tacit knowledge into comprehensible form. Combination is the conversion of explicit knowledge into the organization's tacit knowledge resting in intangible form. It is transformed and shared into tacit form.

Tacit to tacit or person to person knowledge transfer is the most effective way to share knowledge because it is more likely to be inter-documented to another person. According to Lee, H. (2000) [14], tacit knowledge transfer may be in spoken word, but also could occur through body language or other actions. Theorists have defined important facts of knowledge to be tacitness, dependence and complexity. Tacit knowledge is highly personal and hard to express in codes (words, numbers, programming languages) as compared to explicit knowledge that is easy to express and qualify (Polanyi, M., 1969) [15]. Tacit knowledge that is found in subjective insights, intuitions, hunches, knowhow and can often only be acquired through experience has a personal quality which makes it hard to formalize and communicate. It is deeply rooted in action, commitment and involvement in a specific context (Nonaka, I., 1994) [13].

\section{Theories That Support Tacit Knowledge Sharing}

\subsection{Constructivism Theory}

Constructivism theory deals with the way people create meaning of the world through a series of individual constructs which refer to the different types of filters we choose to place over our realities to change our reality from chaos to order. Polanyi, M. (1969) [15] describes constructivism as a theory of knowledge with roots in philosophy, psychology and cybernetics; it's a learning process which allows a learner to experience an environment first hand thereby giving the leaner reliable, trustworthy knowledge. There are several authorities that are behind this theory. Dewey, J. (2009) [16] noted that learners are observers, participants and agents who actively generate and transform patterns through which they construct the realities that fit them. Kolb, D. (1984) [17] emphasizes the importance of conditionalised knowledge through experiential learning. He and Roger Fry 
created the Kolb and Fry Model out of four elements: concrete experience, observation and reflection, the formation of abstract concepts and testing in new situations. Their view is that learning is a continuous spiral and can begin at any one point and that it begins with a person carrying out a particular action and then seeing the effect of the action in this situation. In this theory, they give generalizations that support tacit knowledge sharing that the nature of the learner has to be self-directed, creative and innovative through analysis, conceptualizations and synthesis of prior experience to create new knowledge.

The other generalization is the importance of the background and culture of the learners. Social constructivism theory encourages the learner to arrive at his version of the truth influenced by his or her background, culture or embedded worldview. This view stresses the importance of the nature of the learner's social interaction with knowledgeable members of the society that makes it possible to acquire social meaning of important symbol systems and learn how to utilize them.

The other generalization is that the responsibility of learning should reside increasingly with the learner (Polanyi, M., 1969) [15]. Social constructivism therefore emphasizes the importance of the learner being actively involved in the learning process.

Another crucial assumption is in regard to motivation. According to Polanyi, M. (1969) [16], sustained motivation to learn is strongly dependent on the learner's confidence in his potential to learn. Social constructivism theory strongly suggests that the process of sharing individual perspectives called collaborative elaboration (Van Meter, P. \& Stevens, J., 2006) [18] results in learners constructing understanding together that which would not be possible alone (Greeno, J. \& Resnick, L., 1996) [19].

\subsection{Self Efficacy Theory}

Self efficacy is a person's belief about their ability to organize and execute courses of action necessary to achieve a goal. Persons with strong efficacy beliefs are more confident in their capacity to execute a behavior. The theory emphasizes that individual self efficacy is influenced through several channels: performance accomplishments i.e. ones personal mastery experiences defined as past successes or failures; vicarious experience: observing others perform threatening activities without adverse consequences that demonstrate that the activity is do-able with a little effort and persistence. Vicarious experience can be enhanced through live modeling (observing others perform an activity), a symbolic modeling verbal persuasion. People believe they can perform a task through use of suggestion, exhortation or self-instruction. Emotional arousal self efficacy is enhanced by diminishing emotional arousals such as fear, stress and physical agitation that are associated with decreased performance. Self efficacy theory encourages tacit knowledge sharing since individuals can observe and model others as they perform and with self belief that they can and with diminished emotional arousals, knowledge sharing is enabled.

\subsection{Nonaka's Model of Knowledge Creation}

Nonaka, I. \& Takeuchi, H. (1995) [9] consider four basic processes of knowledge dynamics namely socialization $\{$ L1 $\}$, externalization $\{$ L2 $\}$, combination $\{$ L3 $\}$ and internalization $\{$ L4 $\}$ (Figure 1).

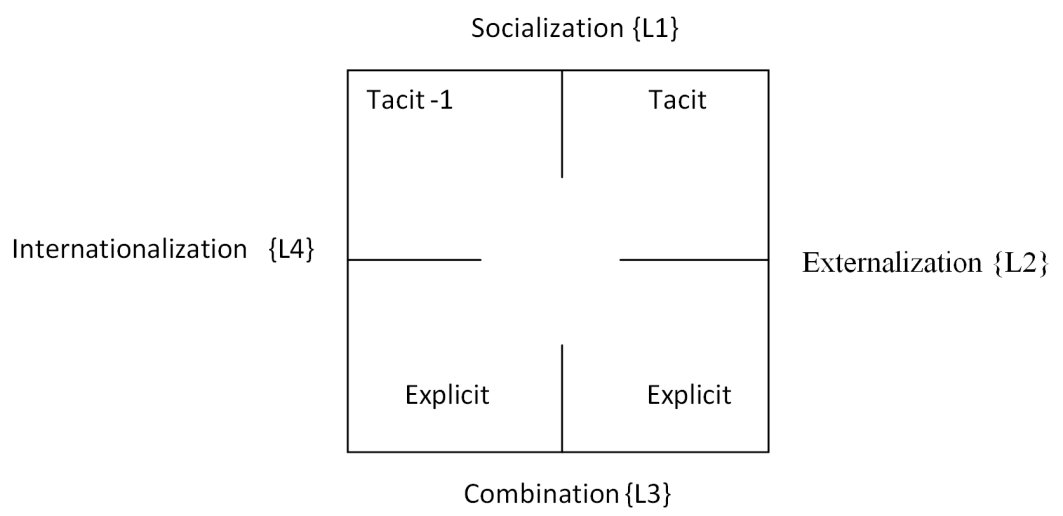

Figure 1. SECI Model of Knowledge Creation Spiral [9]. Source: Nonaka, I. \& Takeuchi, H. (1995). 
Out of the four; two of them satisfy the condition of transforming one form of knowledge into another form. They are externalization and internalization. Externalization $\{\mathrm{L} 2\}$ means to get some explicit knowledge out of experience in a form that can be transferred through the process of combination $\{\mathrm{L} 3\}$. It is tacit knowledge that turned into explicit like say through publishing or other means of articulating knowledge like documents, diagrams and images. Internalization $\{\mathrm{L} 4\}$ is the reverse process by some valuable knowledge which is got through combination that can be stored in a specific way or an experience that is used in decision making. It is the ability to make sense out of learnt concepts or ideas. The other two are the ones that relate to tacit knowledge sharing: socialization $\{\mathrm{L} 1\}$ which involves face to face social interactions and experiences as in meetings, brainstorming sessions and living or spending time together. Combination refers to the different types of explicit knowledge that is transformed into new knowledge. The following diagram shows knowledge spiral

In this model, knowledge is continuously converted and created as users practice and learn. The process should be dynamic, continuous and a swirl of knowledge.

Effective knowledge management must therefore take into account the different methods described above to adopt the right strategy to support knowledge creation and transfer.

Socialization reflects tacit to tacit knowledge exchange or transfer through shared experiences. However, since tacit knowledge is context-specific and therefore people can share through joint activities. Szulanski, G. (1996) [20] says that due to the stickiness of tacit knowledge, it depends highly on the organizational culture and the balance between individual competition and group cooperation.

\section{Empirical Review}

Knowledge sharing in organizations is of great interest to researchers and practitioners alike. Both report that KS improves organizational performance (Lesser, L. \& Storck, J., 2009) [21], promotes competitive advantage (Argote, L. \& Ingram, P., 2008) [22]; and organizational learning (Argote, L., 1999) [23]. It is an integral part of any growing organization (for people need to sharpen one another) (Powell, W., et al. 1996) [24] for its survival (Baum, J. \& Ingram, P., 1998) [25].

A study by Gau, W.-B. (2011) [26] reviewed that knowledge transferring within an organization determines organizational efficiency. The Africa Public Sector Human Resource Management Managers' Network (APS-HRMnet) credits knowledge, knowhow and skills, networks and attitude of personnel in the public sector as the nerve centre of organizational performance. The major observation is that it is through them that services are planned and delivered and that reforms of critical innovations which are realized and needed carried out. How to pass various types of knowledge effectively to organizational members is crucial but the most difficult area of KM is dealing with tacit knowledge. Gau, W.-B. (2011) [26] notes that a message which has not been digested by an individual can only be viewed as data or information rather than knowledge. The process of disseminating and digesting information in an organization can be classified as organization's learning behavior. Therefore tacit knowledge sharing is closely related to organizational learning (Finger, M. \& Brand, S., 1999) [27].

Although organizations may be able to learn things by themselves, the KM mechanism in a governmental organization is especially pregnant with meaning. The public sector has a strict division of labour and therefore there is no incentive to cause public servants to want to look after other colleague's business. This situation makes knowledge delivery and sharing in the public sector more difficult than that in the private sector. Public sector interactions are limited and directed and this hinders knowledge creation and sharing (Gau, W.-B., 2011) [26]. He feels that if the public sector has no appropriate mechanism to create and share tacit and explicit knowledge, the government will not be able to provide the public with quality services, not to mention anything on the country's development.

Blackler, F. (1995) [28] identifies 5 classifications of knowledge: embrained, embodied, encultured, embedded and encoded. Spender, J. (1996) [29] concluded that there are different types of knowledge: conscious, objectified, automatic and collective.

\section{Why Knowledge Sharing Is Important}

Today, the creation and application of new knowledge is essential to the survival of almost all businesses; reason being that it includes intangible products like ideas and processes that give organizations sustainable competitive advantage that enhances continuous innovation. Another importance of tacit knowledge sharing is for 
organizations to tap from the rich experiences of people who have worked there for a long time since if they do not tap these experiences, people leave the organization and consequently theie knowledge walk out of the door with them. This is made worse by the increased turnover of staff and forces of natural attrition. Sharing knowledge also leverages expertise across the organization and this accelerates change. What motivates people to share knowledge is because knowledge is perishable. It is short lived and rapidly loses value if not utilized. It is also obvious that if one does not put knowledge into productive use, someone else with the same knowledge will. Sharing knowledge is a synergistic process that involves one getting more out of it than he puts in. Sharing is about soliciting for feedback, asking questions and telling people what you need to do before doing it. It involves asking other people for help or to work with in some way, however small, telling people what you are doing and more importantly why you are doing it, asking people what they think, asking them for advice and not just sharing information but knowhow and know why. It is about being open in your way of work and relationship with other people

\section{Factors That Influence Tacit Knowledge Sharing}

Many factors influence the way tacit knowledge is shared in organizations. Chief among those factors are explained below.

\subsection{Functional Boundaries}

Functional boundaries refer to restrictions that exist between different sections or departments that may interfere with free tacit knowledge sharing. McEvily, R. (2003) [30] in their study found out that both tacit and explicit knowledge are easier to transfer over strong ties which are prevalent in team environment. Hansen, E. et al. (1999) [31] in his study measured the strength of this observation by asking respondents about relationship closeness and frequency of communication with each contact. In his study, McEvily, R. (2003) [30] endeavored to establish the intensity KS based on duration of interactions. He brought out the issue of duration of interactions and observed that the relationships were really tight in long hours of spending time together. He also brought out the fact that the relationships must be developed over a number of years to develop trust. He also noted that the individuals must work very closely and have very strong bonds. It shows collaboration of people from different units which shows that these collaborations are beneficial if not crucial to the success of the organization. Members are simultaneously involved in more than one production unit at a time and this influences knowledge flow. These ties are very strong and enriching and contribute to organizational knowledge sharing. Cross, R. \& Cummings, J. (2004) [32] observed in their study that where KS is high, it is difficult to draw a line in the lives of the unit of the organization. Kleinner, A. \& Roth, G. (1997) [33] propose the concept of community story telling. That community undertakes work and writes down their knowhow and as Ardichyili, A. et al. (2003) [34] confirms, tacit knowledge is embedded in organizational stories and delivered by organizational members through interactions. However, he observes that three keys issues may hinder knowledge sharing: other peoples (feeling), the trait of tacit knowledge and participant's attitude to interactions. We found out in his study that people hide the skills they have as a survival tip to avoid facing the danger of being replaced by others who become more knowledgeable, and to keep their superior status in the organization.

Wenger, E. (1998) [35] notes that tacit knowledge needs to be consciously digested from members and that individual's tacit knowledge cannot be transferred into organizational knowledge without individuals' acceptance and reflection.

\subsection{Motivation}

Motivation is the morale, zeal, enthusiasm or interest in undertaking an activity without being forced or coerced. Dyer, J. \& Noboeka, K. (2001) [36] in their study showed that non-financial incentives improve KS across organizational boundaries. The motivation for good KS and collaboration is not financial but rather the reputation of an individual. Alavi, M. \& Natalie, S. (2001) [37] notes that KS can be characterized by transferring a complete chunk of knowledge from one person to another and that it involves the "sharers" and receiver who play interchanging roles constantly. He notes that this can only be possible if they are highly motivated. The rewards can be in form of salaries, bonus payments and stock options. Other intangible rewards may be tied to skills gained, assessment of KS being form of tangible reward and the reciprocal access gained to information and knowledge. People understand that if they share, they will be offered something in return. 
The individuals desire to share knowledge and his or her attitude to interactions is important keys to transferring tacit knowledge from the individual to the organizational level. Mazutsi, D. \& Slawinski, N. (2008) [38] assume that dialogue is the core of organizational learning; but they say that communication alone is not satisfactory and that methods to motivate mentors and mentees must be established to let them accept the roles and tasks of knowledge sharing.

Tacit knowledge can be delivered through apprenticeship but the learners' and mentors' attitudes to interactions determine whether the learning culture or knowledge delivery will be successful.

\subsection{Organizational Culture}

One of the biggest challenges in deriving business value from organizational KS is to ensure that KS becomes part of organizational culture. This can be done through developing a KS culture of trust and openness. To assess the culture of an organization, the following should be considered according to Chaffey, D. \& Wood, S. (2005) [39]: The history of the organization. This should be done with the following questions in mind.

i) Does the organization have a history of secrecy i.e. are there particular events that have compounded these problems?

ii) Does the size or geographical scope inhibit KS i.e. are organizational units too large or too small?

iii) Does technology or use of information communication technology increase information over load?

iv) Does leadership or senior managers openly discuss issues and encourage communication from all levels of the organization?

Dixon, M. (1999) [40], in his study focused on people side of management sharing and said that the most effective KS tool is conversations; that the words we choose, the questions we ask, and the metaphors we use to explain ourselves are what determine our successes in creating new knowledge as well as sharing that knowledge with each other. Culture refers to the set of important understanding (often unstated) that members of a community share in common e.g., norms, values, attitudes, beliefs and paradigm. It is the integrated pattern of human behavior that includes thoughts, speech, action and artifacts and depends on man's capacity for learning and transmitting knowledge to succeeding generations.

Organization culture is a relatively rigid tacit infrastructure of ideas that shape not only our thinking but also our behavior and perception of our business environment. It establishes a set of guidelines by which members of an organization work and how those organizations are structured.

\subsection{Communication}

Some scholars such as Faulkner, W. et al. (1995) [41] think that dividing knowledge into tacit and explicit types is inappropriate. They argue that people explain what they see and what they know in their own experience. These experiences are usually in a tacit form. Therefore, even when people are delivering explicit information they express both tacit and explicit knowledge. Kleinner, A. \& Roth, G. (1997) [33] suggest using "teaming slangs" to record important events to help organizational sharing. The purpose is to make use of a double column table to describe and analyze knowledge gained. On one column, the interviewees record their experiences and on another column, historians give their comments or analysis. Such learning history is a base for coping with similar difficulties in the future.

Schwarzwalder, R. (1999) [42] view about knowledge sharing is exposed when he views data as raw material that when selected and given associated meaning, becomes information, which is then shared. He suggests taking advantage of three elements: key persons, the knowledge sharing process and technology communities to encourage knowledge sharing. He suggests that establishing an appropriate environment where communication can openly and freely proceed is the core of knowledge management. Zack, M. (1999) [43] advocates for taking advantage of it to support knowledge sharing but this may not be achieved if an organization cannot electronically collect, index store and distribute explicit knowledge more readily usable anywhere, anytime.

Wenger, E. (1998) [35] in his study established from his respondents that in order to motivate employees to participate in KS activities both hardware (facilities of delivering knowledge) and software (the whole situation of knowledge sharing) must be taken into account. He advocates for repetitious communication to facilitate the delivery of tacit knowledge. The public service is a fixed and big system. Most of the routines and processes have been regulated by the law.

Technology plays a crucial transformational role and is a key part of changing the corporate culture to know- 
ledge sharing one. People have to be trained and educated in technology use so that knowledge can be posted in organizational systems for use.

The two most important factors in knowledge sharing are people with the appropriate knowledge sharing mindset and the appropriate knowledge sharing technology to support the sharing.

\section{Conclusion}

From the review, it can be concluded that many people are not cognizant of tacit knowledge sharing and worse still, they do not know the meaning of the concept. People have shared both tacit and explicit knowledge but they give no attention to that hidden knowledge deeply ingrained in our minds and which comes out only through interactions and observations. It can also be concluded that though tacit knowledge plays a more crucial role in organizational performance than explicit knowledge, people continue paying little attention to it even when it is the only non-imitable knowledge as long as it has not been transformed into explicit knowledge through externalization. It is crystal clear that the public sector does not have a healthy platform for sharing knowledge, because of the factors discussed earlier in this review. The private sector could be better off since even if these factors still interplay, the employees can be compelled to share through threats or even punishments. In this knowledge age, organizations have no choice but to conform to the changing times. The world is going or is already digitalized and this means that a lot of contribution in form of knowledge is needed to bring about new inventions and also innovations.

\section{Recommendations}

The review recommends the following.

i) The public sector must choose, without being coerced, to facilitate tacit knowledge sharing so as to be competitive since even if they are not profit-making organizations, they require earnings for maintaining their facilities.

ii)The public sector should endeavor to create flatter organizations which is devoid of functional barriers, protocol or hierarchy that delays or hinders tacit knowledge sharing since out of the 4 m's of organizational resource namely man, material, machines and resources, only man can give competitive advantage.

iii) Communication in organizations should be vertically upwards and vertically downwards and also horizontally direct and horizontally indirect. These allow for free and open communication that also gives room for feedback.

iv) With the individualism that comes with modernization and urbanization, and given that most of the public institutions are in urban or semi-urban areas, the public sector has no choice but to adopt ways of ensuring free information flow so that knowledge can be leveraged.

v) Employees must be encouraged to deliberately share knowledge. This should involve appropriate motivation which should be based on the hierarchy of needs as was advanced by Abraham Maslow since tacit knowledge sharing does not discriminate. All levels of employees need to share knowledge.

vi) The workforce should also be encouraged to develop organizational contract which ensures that as they pursue individual goals, they choose without being coerced to prioritize organizational goals.

vii) The distance between people working together should be reduced since knowledge sharing is a pooled endeavour that requires effort, alliances and enhanced networking amongst sharers.

viii) Communities of practice should be encouraged to create unity in people who have common skills, talents and interests.

ix) Encourage a corporate culture that prioritizes knowledge sharing in all organizational rituals.

\section{References}

[1] Senge, P. (1990) The Fifth Discipline: The Art and Practice of the Learning Organization. Doubleday Business, London.

[2] Drucker, P. (1999) Knowledge-Worker Productivity: The Biggest Challenge. California Management Review, 41, 7994. http://dx.doi.org/10.2307/41165987

[3] Strassmann, P. (1985) Information Pay Off: The Transformation of Work in the Electronic Age. The Free Press, New York.

[4] Everett, R. (1970) Diffusion of Innovation: Critical Perspective. Sage, Beverly Hills. 
[5] Allen, T.J.G. (2006) The Organization Architecture of Innovation: Managing the Flow of Technology. ButterworthHeinemann Ltd., Oxford, 152.

[6] Sakaiya, T. (1999) The Knowledge-Value Revolution, or, a History of the Future. Kodansha America, Inc., New York.

[7] Senge, P., et al. (1994) The Fifth Discipline Field Book Strategies and Tools for Building a Learning Organization. Currency Doubleday, New York.

[8] Augus, J. and Jeeto, P. (1998) Knowledge Management: Great Concept.....But What Is It? Information Week, No. 673, 58-70.

[9] Nonaka, I. and Takeuchi, H. (1995) The Knowledge-Creating Company: How Japanese Companies Create the Dynamics of Innovation. Oxford University Press, New York.

[10] Dougherty, V. (1999) Knowledge about People, not Databases. Industrial and Commercial Training, 31, 262-266. http://dx.doi.org/10.1108/00197859910301962

[11] Polanyi, M. (1962) Personal Knowledge: Towards a Post-Critical Philosophy. Psychology Press, Location.

[12] Kogut, B. and Zander, U. (1992) Knowledge of the Firm, Combinative Capabilities, and the Replication of Technology. Organization Science, 3, 383-397. http://dx.doi.org/10.1287/orsc.3.3.383

[13] Nonaka, I. (1994) A Dynamic Theory of Organizational Knowledge Creation. Organization Science, 5, 14-37. http://dx.doi.org/10.1287/orsc.5.1.14

[14] Lee, H. (2000) Knowledge Management Enablers, Processes, and Organizational Performance: An Integration and Empirical Examination. Journal of Management Information Systems, 20, 179-228.

[15] Polanyi, M. (1969) Knowing and Being. Chicago University Press, Chicago.

[16] Dewey, J. (2009) Between Pragmatism and Constructivism. Fordham, American Philosophy, Fordham University Press, Enhancing Professionalization of Human Resource Management Managers' Network (APS-HRMnet), Bronx.

[17] Kolb, D. (1984) Experiential Learning: Experience as the Source of Learning and Development. Prentice Hall, Englewood Cliffs.

[18] Van Meter, P. and Stevens, R.J. (2000) The Role of Theory in the Study of Peer Collaboration. Journal of Experimental Education, 69, 113-129.

[19] Greeno, J., Collins, A. and Resnick, L. (1996) Cognition and Learning. In: Calfree, R. and Berliner, D., Eds., Handbook of Educational Psychology, Macmillan, New York, 15-46.

[20] Szulanski, G. (1996) Exploring Internal Stickiness: Impediments to the Transfer of Best Practice within Firms. Strategic Management Journal, 17, 27-43. http://dx.doi.org/10.1002/smj.4250171105

[21] Lesser, L. and Storck, J. (2001) Communities of Practice and Organizational Performance. IBM Systems Journal, 40, 831-841.

[22] Argote, L. and Ingram, P. (2000) Knowledge Transfer: A Basis for Competitive Advantage in Firms. Organizational Behavior and Human Decision Processes, 82, 150-169.

[23] Argote, L. (1999) Organizational Learning: Creating, Retaining, and Transferring Knowledge. Khiwer Academic Publishers, Norwell.

[24] Powell, W., Koput, K.W. and Smith-Doerr, L. (1996) Interorganizational Collaboration and the Locus of Innovation: Networks of Learning in Biotechnology. Administrative Science Quarterly, 41, 116-145. http://dx.doi.org/10.2307/2393988

[25] Baum, J. and Ingram, P. (1998) Survival-Enhancing Learning in the Manhattan Hotel Industry, 1898-1980. Management Science, 44, 996-1016. http://dx.doi.org/10.1287/mnsc.44.7.996

[26] Gau, W.-B. (2011) A Study of Tacit Knowledge Management in the Public Sector. Journal of Knowledge Management Practice, 12.

[27] Finger, M. and Brand, S.B. (1999) The Concept of the "Learning Organization” Applied to the Transformation of the Public Sector: Conceptual Contributions for Theory Development. In: Easterby-Smith, M., Araujo, L. and Burgoyne, J., Eds., Organizational Learning and the Learning Organization: Developments in Theory and Practice, Sage, London.

[28] Blackler, F. (1995) Knowledge, Knowledge Work and Organizations: An Overview and Interpretation. Organization Studies, 16, 1021-1046. http://dx.doi.org/10.1177/017084069501600605

[29] Spender, J. (1996) Making Knowledge the Basis of a Dynamic Theory of the Firm. Strategic Management Journal, 17, 45-62.

[30] McEvily, R. (2003) Network Structure and Knowledge Transfer. Bureau of Economic Survey, Administrative Science Quarterly, 48, 240-267. http://dx.doi.org/10.2307/3556658

[31] Hansen, M., Nohria, N. and Tierney, T.J. (1999) What’s Your Strategy for Managing Knowledge? Harvard Business Review, 23, 106-116. 
[32] Cross, R. and Cummings, J. (2004) Tie and Networks Correlates of Individual Performance in Knowledge-Intensive Work. Academy of Management Journal, 47, 928-937. http://dx.doi.org/10.2307/20159632

[33] Kleiner, A. and Roth, G. (1997) How to Make Experience Your Company’s Best Teacher. Harvard Business Review, 75, 172-177.

[34] Ardichvili, A., Page, V. and Wentling, T. (2003) Motivation and Barriers to Participation in Virtual Knowledge Sharing Communities of Practice. Journal of Knowledge Management, 7, 64-77. http://dx.doi.org/10.1108/13673270310463626

[35] Wenger, E. (1998) Communities of Practice: Learning, Meaning and Identity. Cambridge University Press, Cambridge. http://dx.doi.org/10.1017/CBO9780511803932

[36] Dyer, J.H. and Noboeka, K. (2001) Creating and Managing a High Performance Knowledge Sharing Network: The Toyota Case. Strategic Management Journal, 21, 345-368.

[37] Alavi, M. and Leidner, D. (2001) Review: Knowledge Management and Knowledge Management Systems: Conceptual Foundations and Research Issues. MIS Quarterly, 25, 107-136. http://dx.doi.org/10.2307/3250961

[38] Mazutis, D. and Slawinski, N. (2008) Leading Organizational Learning through Authentic Dialogue. Management Learning, 39, 437-456. http://dx.doi.org/10.1177/1350507608093713

[39] Chaffey, D. and Wood, S. (2005) Business Information Management: Improving Performance Using Information. Pearson Education Ltd., Upper Saddle River.

[40] Dixon, M. (1999) The Organizational Learning Cycle: How Can We Learn Collectively. Gower Publishing Ltd., Hampshire.

[41] Faulkner, W., Senker, J. and Velho, L. (1995) Knowledge Frontiers: Public Sector Research and Industrial Innovation in Biotechnology, Engineering Ceramics and Parallel Computing. Oxford University Press, Oxford. http://dx.doi.org/10.1093/acprof:oso/9780198288336.001.0001

[42] Schwarzwalder, R. (1999) Librarians as Knowledge Management Agents. Econtent, 22, 63-65.

[43] Zack, M. (1999) Managing Codified Knowledge. Sloan Management Review, 40, 45-58. 
Scientific Research Publishing (SCIRP) is one of the largest Open Access journal publishers. It is currently publishing more than 200 open access, online, peer-reviewed journals covering a wide range of academic disciplines. SCIRP serves the worldwide academic communities and contributes to the progress and application of science with its publication.

Other selected journals from SCIRP are listed as below. Submit your manuscript to us via either submit@scirp.org or Online Submission Portal.
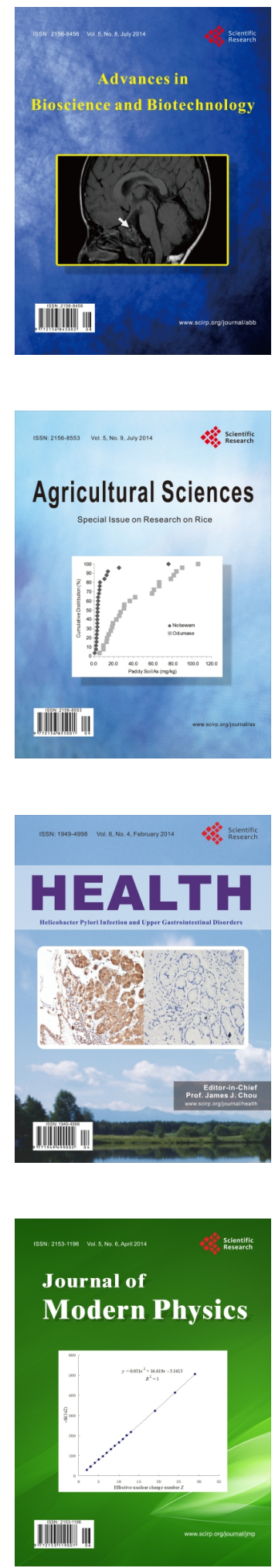
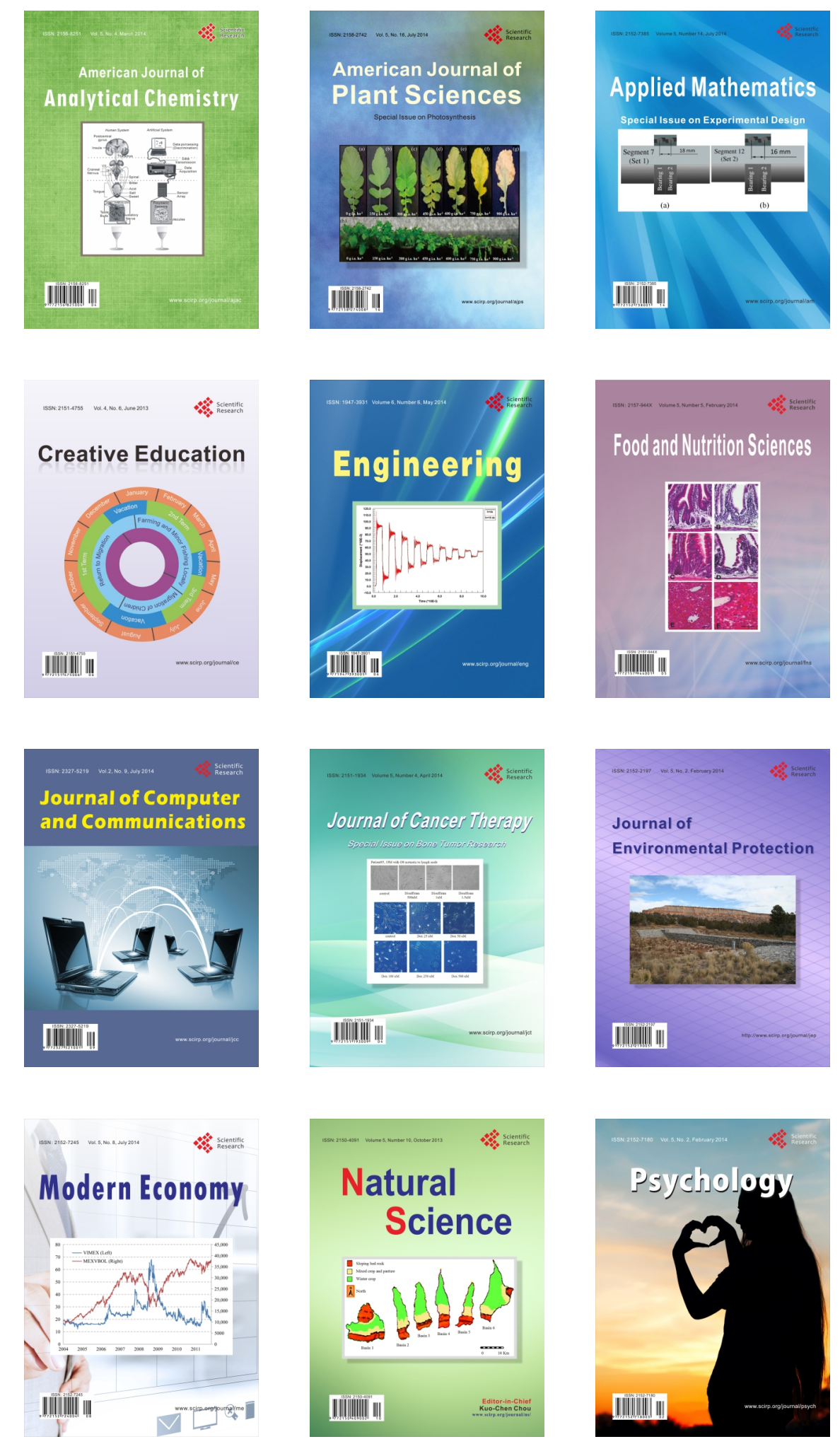